http://vektor.iain-jember.ac.id

\title{
TECHNOLOGICAL PEDAGOGICAL CONTENT KNOWLEDGE MAHASISWA CALON GURU BIOLOGI DALAM MENYUSUN PERANGKAT EVALUASI PEMBELAJARAN
}

\author{
Nukhbatul Bidayati Haka1*, Rizka Yohana2, Laila Puspita ${ }^{3}$ \\ ${ }^{1}$ Dosen Program Studi Pendidikan Biologi Universitas Islam Negeri Raden Intan Lampung, \\ Lampung, Indonesia \\ 2 Program Studi Pendidikan Biologi Universitas Islam Negeri Raden Intan Lampung, Lampung, \\ Indonesia \\ 3 Dosen Program Studi Pendidikan Biologi Universitas Islam Negeri Raden Intan Lampung, \\ Lampung, Indonesia
}

\author{
*Corresponding Author: nukhbatulbidayatihaka@radenintan.ac.id
}

\begin{abstract}
Abstrak. Guru merupakan figur sentral dalam penyelenggaraan pendidikan. Dalam proses pembelajaran guru tidak hanya melakukan transfer ilmu tetapi harus memiliki kuaifikasi akademik yang sesuai bidang, kompetensi teknologi, pedagogik, personal, dan persyaratan profesionalitas yang mumpuni. Penelitian ini bertujuan untuk mengetahui kemampuan Technological Pedagogical Content Knowledge (TPCK) mahasiswa calon guru Pendidikan Biologi UIN Raden Intan Lampung dalam menyusun perangkat evaluasi pembelajaran. Jenis penelitian ini adalah kuantitatif dengan metode analisis korelasi. Penentuan partisipan dalam penelitian ini dilakukan dengan teknik purposive sampling yaitu mahasiswa pendidikan biologi angkatan 2016 semester 8 yang sudah menyelesaikan materi pedagogik. Teknik pengumpulan data menggunakan angket, lembar obseravasi, wawancara dan dokumentasi. Uji hipotesis pada penelitian ini menggunakan uji korelasi Product Moment. Hasil analisis korelasi memperoleh nilai koefisien korelasi sebesar 0,585 yang mneunjukan hubungan antara dua vriabel tersebut cukup kuat dan arah hubungan menunjukan arah positif, maka Ho ditolak dan Ha diterima artinya terdapat hubungan yang positif antara kemampuan Technological Pedagogical Content Knowledge (TPCK) dengan kemampuan membuat perangkat Evaluasi Pembelajaran pada mahasiswa.
\end{abstract}

Kata Kunci: calon guru, kemampuan technological pedagogical content knowledge, perangkat evaluasi pembelajaran

\begin{abstract}
The teacher is a central figure in the administration of education. In the learning process the teacher does not only transfer knowledge but must have academic qualifications in accordance with the fields, technological competence, pedagogic, personal, and qualified professional requirements. This study aims to determine the ability of Technological Pedagogical Content Knowledge (TPCK) for prospective teachers of Biology Education at UIN Raden Intan Lampung in developing learning evaluation tools. This type of research is quantitative with correlation analysis method. Determination of participants in this study was conducted with a purposive sampling technique, namely biology education students for semester 82016 who had completed pedagogic material. Data collection techniques using questionnaires, observation sheets, interviews and documentation. Hypothesis testing in this study uses the Product Moment correlation test. Correlation analysis results obtained a correlation coefficient of 0.585 which shows the relationship between the two variables is quite strong and the direction of the relationship shows a positive direction, then $\mathrm{Ho}$ is rejected and $\mathrm{Ha}$ is accepted, meaning there is a positive relationship between the ability of Technological Pedagogical Content Knowledge (TPCK) with the ability to make evaluation tools Student learning.
\end{abstract}

Keywords: knowledge skills in technology pedagogical content, learning evaluation devices, teacher candidates 


\section{PENDAHULUAN}

Guru merupakan pihak yang terlibat langsung dalam proses pembelajaran yang menjadikan faktor utama dalam penentu mutu pendidikan. Pada era global, mengharuskan pendidikan yang berkualitas dan profesional. Pendidikan merupakan upaya memberikan pengetahuan, wawasan, keterampilan dan keahlian tertentu kepada individu guna mengembangkan bakat serta kepribadian mereka (Aulia Novitasari. Alinis Ilyas. Siti NA 2017). Technological Pedagogical Content Knowledge (TPCK) dikenal didalam bidang penelitian pendidikan sebagai kerangka teoritis untuk memahami pengetahuan yang dibutuhkan oleh guru untuk mengintegrasikan tiga domain pengetahuan teknologi, pedagogi, dan konten. Menurut hasil penelitian Schoen dan Fusarelli bahwa kemampuan pedagogik guru dan penggunaan teknologi informasi dan komunikasi sebagai alat instruksional merupakan faktor yang membantu dalam proses kegiatan belajar mengajar disekolah.

Penelitian lainnya menyatakan bahwa integrasi TPCK dinilai mampu meningkatkan kemampuan belajar peserta didik, namun hal ini tidak selalu tercapai karena kurangnya kemampuan implementasi produktif dari pengetahuan teknologi yang tepat dalam proses pembelajaran. Dalam penelitian Saadah, menyatakan bahwa diperlukannya upaya mengatasi kesulitan mahasiswa calon guru dan guru dalam mengintegrasikan TPACK pada pembelajaran. Kerangka TPCK diadopsi dari konstruksi Schulman tentang PCK dengan memasukkan pengetahuan teknologi yang ditempatkan bersama dengan pengetahuan konten dan pedagogik (Nurul 2017). Dalam dunia pendidikan pengertian teknologi pada abad ke-20 meliputi lentera pertama proyektor slide, radio dan gambar hidup sedangkan pada abad ke-15 sampai ke-19 teknologi lebih diartikan papan tulis dan buku. Perkembangan teknologi yang semakin maju dari tahun ketahun memudahkan dalam merumuskan konsep-konsep baru yang mengaitkan pembelajaran dengan teknologi (Dwi Anis AD 2017). Mengintegraikan teknologi kedalam pembelajaran merupakan kerangka untuk menjelaskan kajian utama Technological Pedagogical Content Knowledge (TPCK) yang mecakup 7 komponen yaitu Technological Knowledge (TK), Technological Content Knowledge (TCK), Technological Pedagogical Knowledge (TPK), Pedagogical Knowledge (PK), Content Knowledge (CK), Pedagogical Content Knowledge (PCK) dan Technological Pedagogical Content Knowledge (TPCK).

Content knowledge mengacu kepada pengetahuan materi subjek yang harus dikuasai saat mengajar, kemampuan tersebut meliputi kesesuain materi, keluasan dan kedalaman materi, dan pengembangan materi (Eka Ariyati., n.d.). Pengetahuan pedagogik merupakan pengetahuan dasar yang harus dimiliki oleh calon guru sebelum melakukan proses pembelajaran dikelas. Pengetahuan pedagogik mencakup perencanaan pembelajaran, menyampaikan materi, mengkondisikan siswa, pemilihan model atau metode, jenis media pembelajaran, evaluasi hasil belajar, pemilihan ranah peniaian, pengembangan peserta didik untuk mengaktualisasikan berbagai potensi yang dimilikinya dan menyampaikan pesan kepada individu-individu yang berbeda (D. Rochintaniawati, R. Riandi 2019).

Pedagoical Content knowledge (PCK) merupakan pengetahuan tentang cara menyajikan materi sehingga mudah dipahami. PCK merupakan kombinasi dua jenis kompetensi yaitu kompetensi pedagogik dan kompetensi profesional yang meliputi kesesuaian materi dengan metode atau model dan evaluasi. Pengetahuan tentang teknologi berkaitan dengan penggunaan teknologi seperti pengoprasian komputer, menggunakan software, hardware, peralatan persentasi seperti dokumen persentasi dan teknologi lainnya dalam konteks pendidikan.

Pengetahuan tentang konten teknologi merupakan hubungan timbal balik antara teknologi dan konten materi. Kemajuan teknologi di era globalisasi ini merupakan salah satu hal yang tidak bisa dihindari dan harus dimanfaatkan untuk mengubah cara memahami konsep materi tertentu. Salah satu wujud dari pengembangan teknologi dalam pendidikan adalah pembuatan media pembelajaran berbasis TIK.TIK sangat 
dibutuhkan sebagai katalisator yakni guna mempermudah pemahaman materi pembelajaran (M.J Koehler, n.d.). Pengetahuan pedaogik merupakan pengetahuan tentang bagaimana beragam teknologi dapat digunakan dalam pengajaran dan penggunaan teknologi tersebut mampu mengubah cara mengajar seorang guru. Kurikulum yang digunakan saat ini terpusat pada siswa (student centered learning) dimana pendidik sekarang tidak lagi menjadi rujukan sau-satunya dalam proses pembelajaran tetapi hanya sebagai fasilitator pembelajaran. Teknologi informasi yang ada saat ini merupakan salah satu cara menjembatani tuntutan kurikulum tersebut.

TPCK meruapakan satuan dari beberapa kompnen kompetensi yang harus dimiliki oleh guru agar dapat mengintegrasikan pengetauannya dengan teknologi. Kemajuan teknologi informasi yang sangat pesat pada akhirnya mendorong guru dan calon guru untuk menguasai teknologi tersebut sebagai media pendukung dalam pembelajaran sesuai dengan tuntutan kurikulum 2013 dimana pendidik harus mampu mengintegrasikan teknologi dalam pembelajaran. TPCK adalah kerangka kerja yang dinamis untuk menggambarkan pengetahuan yang dapat diandalkan oleh guru dalam merancang dan mengimplementasikan kurikulum dan pembelajaran, disamping membimbing peserta didik untuk berpikir dan belajar dengan menggunakan teknologi. Teknologi bisa dibuat dengan khas untuk dihadapkan pada kebutuhan pedagogis untuk mengajar konten yang tepat dalam konteks tertentu. Kerangka TPCK mendeskripsikan berbagai jenis pengetahuan yang guru dan calon guru butuhkan untuk mengajar efektif dengan bantuan teknologi dan berbagai prosedur kompleks dalam bidang interaksi pengetahuannya (Nur Atikah 2019).

Guru sains harus memiliki pengetahuan mengenai peserta didik, kurikulum, strategi intruksional, dan assesmen sehingga dapat melakukan transformasi science knowledge dengan efektif (Sri 2017). Kurikulum yang berlaku saat ini adalah kurikulum 2013 yang dikatakan sebagai sebuah sistem atau pendekatan pembelajaran yang melibatkan beberapa disiplin ilmu untuk memberikan pengalaman yang bermakna dan luas kepada peserta didik. Tujuan kurikulum 2013 adalah mempersiapkan manusia agar memiliki kemampuan hidup sebagai pribadi dan warga negara yang beriman, produktif, kreatif, inofatif dan afektif serta mampu berkontribusi dalam kehidupan bermasyarakat. Oleh karena itu, guru sebagai pembimbing memfasilitasi kegiatan siswa agar tercapainya kompetensi yang telah dirancang dalam dokumen kurikulum. Kemampuan kreatifitas seseorang diperoleh melalui pendidikan dan faktor genetik. Pada penerapan kurikulum 2013 guru juga dituntut untuk menerapkan teknologi pada pembelajaran sehingga mampu mengakomodasi kecenderungan cara belajar yang mereka miliki, salah satunya dengan pemilihan model pembelajaran yang sesuai dengan karakteristik peserta didik yang bersifat aplikatif dan menyenangkan. Oleh karena itu isu terkini menyebutkan bahwa seorang guru harus memiliki kemampuan Technological Pedagogical Content Knowledge (TPCK) secara baik.

Kemampuan Technological Pedagogical Content Knowledge (TPCK) sangat diperlukan untuk meningkatkan kualitas lulusan sesuai dunia kerja dan tuntutan teknologi digital. Metode pembelajaran pendidikan Indonesia harus mulai beralih menjadi proses-proses pemikiran yang visioner, termasuk mengasah kemampuan cara berpikir kreatif dan inovatif. Hal ini diperlukan untuk menghadapi berbagai perkembangan teknologi dan ilmu pengetahuan. Namun, kebanyakan mahasiswa calon guru masih memiliki pemahaman yang kurang terkait penguasaan materi/konten, lemah dalam memahami kurikulum, penyusunan instrumen-instrumen pembelajaran dan belum mampu untuk mengintegrasikan teknologi kedalam pembelajaran secara tepat dengan berlandasan dengan kurikulum.

Standar penilaian pendidikan berhubungan dengan prosedur, mekanisme, serta instruemen dari penilaian hail belajar peserta didik. Salah satu komponen yang harus dikuasai oleh guru adalah evaluasi pembelajaran. Kompetensi tersebut sejalan dengan instrumen penilaian kemampuan guru, yang salah satu indikatornya adalah melakukan evaluasi pembelajaran (Zainal Arifin 2013). Selain kemampuan TPCK dalam proses 
pembelajaran evaluasi sangat diperlukan untuk mengukur dan menilai peserta didik dengan menggunakan alat tes maupun non tes. Evaluasi pembelajaran sangat penting dilakukan untuk mengetahui efektif atau tidaknya suatu sistem pembelajaran yang diterapkan oleh pendidik. Tenaga pendidik harus menciptakan inovasi baru untuk memperbaharui sistem pembelajaran yang diterapkan mulai dari materi, pemilihan model dan strategi pembelajaran, media pembelajaran, sumber belajar, dan sistem penilaian agar pendidikan tidak terkesan monoton dan dapat meningkatkan semangat belajar pada peserta didik. Keberhasilan suatu kegiatan evaluasi akan dipengaruhi pula oleh keberhasilan evaluator dalam melaksanakan prosedur evaluasi. Prosedur pengembangan evaluasi pembelajaran terdiri atas: (1) perencanaan evaluasi yang meliputi analisis kebutuhan, merumuskan tujuan evaluasi, menyusun kisi-kisi, mengembangkan draf instrumen, uji coba dan analisi, merevisi dan menyusun instrument final, (2) pelaksanaan evaluasi dan monitoring, (3) pengolahan data dan analisis, (4) pelaporan hasil evaluasi dan (5) pemanfaatan hasil evaluasi (Zainal Arifin 2013).

Upaya dalam meningkatkan dan mengembangakan TPCK calon guru dan guru membutuhkan pengembangan dan peningkatan terhadap pengetahuan mahasiswa calon guru akan hubungan yang kompleks antara pedagogik, konten dan teknologi karena dengan pemahaman tersebut dapat digunakan untuk mengembangkan strategi, pendekatan, media, metode, dan teknik pengajaran yang sesuai dengan permintaan kurikulum. Berdasarkan pemaparan diatas, analisis profil tentang kemampuan TPCK mahasiswa calon guru Pendidikan Biologi UIN Raden Intan Lampung perlu dilakukan sebagai bahan evaluasi untuk mengetahui kesiapan mahasiswa calon guru dalam menghadapi problematika pendidikan. Hal tersebut merupakan kebutuhan kontinu untuk memikirkan kembali praktik persiapan calon guru dengan mengusulkan strategi baru yang lebih mempersiapkan diri untuk mengintegrasikan teknologi ke dalam pengajaran mereka serta mengasah keterampilan dalam menyusun perangkat evaluasi pembelajaran yang di perlukan sebagai tolak ukur keberhasilan dari pembelajaran yang sudah diterapkan. Berdasarkan uraian permasalahan diatas sangat diperlukan pengasahan untuk meningkatkan kemampuan TPCK mahasiswa calon guru dalam menyusun perangkat evaluasi pembelajaran guna meningkatkan kualitas dan profesionalitas dalam kegiatan belajar mengajar agar tercapainya tujuan pendidikan nasional dan terpenuhinya tuntutan pendidikan yang tercantum pada kurikulum 2013, dengan mengetahui tingkat kemampuan yang dimiliki sebagai bahan evaluasi. . Berangkat dari hal tersebut, peneliti tergerak untuk melakukan penelitian dengan judul "Analisis Kemampuan Technological Pedagogical Content Knowledge Mahasiswa Calon Guru Pendidikan Biologi UIN Raden Intan Lampung Dalam Menyusun Perangkat Evaluasi".

\section{METODE}

Desain penelitian yang digunakan adalah kuantitatif dengan jenis penelitian analisis korelasi. Metode penelitian analisis korelasi dipilih karena akan mempelajari hubungan antara dua variabel atau lebih, yakni hubungan variasi dalam satu variabel dengan variasi dalam variabel lain. Dalam hal ini akan meihat kemampuan Technological Pedagogical Content Knowledge (TPCK) yang dikaitkan dengan kemampuan dalam menyusun perangkat evaluasi pembelajaran pada mahasiswa Pendidikan Biologi UIN Raden Intan Lampung. Populasi pada penelitian ini yaitu mahasiswa calon guru Pendidikan Biologi UIN Raden Intan Lampung angkatan 2016 sebanyak 242 mahasiswa dengan syarat yang sudah mengambil mata kuliah PPL dan KKN serta telah menyelesaikan materi pedagogik di PSPB. Sampel yang diambil pada penelitian ini adalah mahasiswa angakatan 2016 semester 8 sebanyak 48 mahasiswa yang sudah mengambil mata kuliah PPL dan KKN serta lulus pada mata kuliah telaah kurikulum, strategi pembelajaran, media pembelajaran, dan evaluasi pembelajaran beserta dosen yang mengampu mata kuliah tersebut. Penentuan partisipan dalam penelitian ini dilakukan 
dengan teknik purposive sampling yaitu teknik penentuan sampel dengan pertimbangan tertentu (Sugiyono. 2017). Instrumen yang digunakan berupa angket, lembar observasi, wawancara dan dokumentasi. Hasil validasi ahli menunjukan bahwa instrumen valid dan siap untuk digunakan. Hasil uji coba menunjukan bahwa instrument yang digunakan valid dn memiliki tingkat reliabilitas yang tinggi. Data hasil penelitian dianalisis secara kuantitatif yaitu uji statistik deskriptif dan uji Korelasi Product Moment.

\section{HASIL DAN PEMBAHASAN}

Penelitian telah dilakukan untuk memperoleh informasi tentang kemampuan TPCK calon guru Pendidikan Biologi. Hasil angket TPCK berdasarkan rata-rata setiap aspek indikator disajikan pada Gambar 1.

Gambar 1. Penilaian angket TPCK

\section{Content Knowledge (CK)}

Berdasarkan analisis data, diketahui kemampuan Content Knowledge (CK) mahasiswa calon guru Pendidikan Biologi UIN Raden Intan Lampung disajikan dalam tabel 1 dibawah ini

Tabel 1. Kemampuan content knowledge (CK).

\begin{tabular}{|c|c|c|c|}
\hline No & Item Pernyataan & Persentase & Kriteria \\
\hline 1 & $\begin{array}{l}\text { Saya mempunyai pengetahuan tentang } \\
\text { materi biologi yang akan saya ajarkan }\end{array}$ & 82 & $\begin{array}{l}\text { Sangat } \\
\text { Baik }\end{array}$ \\
\hline 2 & $\begin{array}{l}\text { Saya cenderung monoton dalam } \\
\text { mengembangkan materi biologi dengan } \\
\text { kompetensi yang akan dicapai }\end{array}$ & 77 & $\begin{array}{l}\text { Sangat } \\
\text { Baik }\end{array}$ \\
\hline 3 & $\begin{array}{l}\text { Saya dapat merancang dan menerapkan } \\
\text { serta mengembangkan ilmu biologi untuk } \\
\text { tujuan pembelajaran yang akan dicapai }\end{array}$ & 100 & $\begin{array}{l}\text { Sangat } \\
\text { Baik }\end{array}$ \\
\hline 4 & $\begin{array}{l}\text { Saya mengikuti perkembangan ilmu } \\
\text { biologi }\end{array}$ & 76 & $\begin{array}{l}\text { Sangat } \\
\text { Baik }\end{array}$ \\
\hline 5 & $\begin{array}{l}\text { Saya menggunakan referensi terbaru } \\
\text { (seperti buku dan jurnal) untuk } \\
\text { menambah pengetahuan biologi }\end{array}$ & 71 & Baik \\
\hline 6 & $\begin{array}{l}\text { Saya mengikuti seminar atau workshop } \\
\text { yang terkait biologi }\end{array}$ & 61 & Baik \\
\hline 7 & $\begin{array}{l}\text { Saya tidak pernah mengikuti seminar/ } \\
\text { workshop terkait biologi }\end{array}$ & 100 & $\begin{array}{l}\text { Sangat } \\
\text { Baik }\end{array}$ \\
\hline 8 & $\begin{array}{l}\text { Saya dapat berpikir seperti seorang ahli } \\
\text { biologi pada saat mengajar }\end{array}$ & 62 & Baik \\
\hline 9 & $\begin{array}{l}\text { Saya tidak menguasai materi biologi yang } \\
\text { akan diajarkan }\end{array}$ & 78 & $\begin{array}{l}\text { Sangat } \\
\text { Baik }\end{array}$ \\
\hline
\end{tabular}

Nukhbatul Bidayati Haka, Rizka Yohana, dkk.: Technological Pedagogical Content Knowledge Mahasiswa Calon Guru Biologi dalam Menyusun Perangkat Evaluasi Pembelajaran 177 


\begin{tabular}{|l|l|c|c|}
\hline Total & 78,5 & $\begin{array}{c}\text { Sangat } \\
\text { Baik }\end{array}$ \\
\hline
\end{tabular}

Kemampuan Content Knowledge (CK) mahasiswa calon guru Pendidikan Biologi UIN Raden Intan Lampung, dikategorikan dalam kriteria sangat baik dengan skor rata-rata $78,5 \%$. Terdapat 3 item yang dikategorikan baik yaitu menggunakan suber-sumber atau referensi terbaru, berfikir seperti ahli biologi dan mengikuti seminar atau workshop terkait biologi.

\section{Pedagogical Knowledge (PK)}

Berdasarkan analisis data, diketahui kemampuan Pedagogical Knowledge (PK) mahasiswa calon guru Pendidikan Biologi UIN Raden Intan Lampung disajikan dalam tabel 2 dibawah ini

Tabel 2. Kemampuan pedagogical knowledge (PK).

\begin{tabular}{|c|c|c|c|}
\hline No & Item Pernyataan & Persentase & Kriteria \\
\hline 1 & $\begin{array}{l}\text { Saya dapat menerapkan strategi } \\
\text { pembelajaran yang bervariasi }\end{array}$ & 72 & Baik \\
\hline 2 & $\begin{array}{l}\text { Saya dapat merencanakan kegiatan } \\
\text { pembelajaran yang menyenangkan } \\
\text { dengan memperhatikan pencapaian } \\
\text { tujuan pembelajaran }\end{array}$ & 75 & $\begin{array}{c}\text { Sangat } \\
\text { Baik }\end{array}$ \\
\hline 3 & $\begin{array}{l}\text { Saya tidak melakukan perencanaan } \\
\text { kegiatan pembelajaran dengan baik }\end{array}$ & 82 & $\begin{array}{l}\text { Sangat } \\
\text { Baik }\end{array}$ \\
\hline 4 & $\begin{array}{l}\text { Saya menyadari kemungkinan terjadinya } \\
\text { miskonsepsi dan kesulitan pada siswa }\end{array}$ & 77 & $\begin{array}{c}\text { Sangat } \\
\text { Baik }\end{array}$ \\
\hline 5 & $\begin{array}{l}\text { Saya acuh terhadap perkembangan ilmu } \\
\text { biologi }\end{array}$ & 83 & $\begin{array}{l}\text { Sangat } \\
\text { Baik }\end{array}$ \\
\hline 6 & $\begin{array}{l}\text { Saya dapat mengelola dan menguasai } \\
\text { kelas dengan baik }\end{array}$ & 77 & $\begin{array}{l}\text { Sangat } \\
\text { Baik }\end{array}$ \\
\hline 7 & $\begin{array}{l}\text { Saya tidak dapat mengkondisikan dan } \\
\text { mengelola kelas dengan baik }\end{array}$ & 80 & $\begin{array}{c}\text { Sangat } \\
\text { Baik }\end{array}$ \\
\hline 8 & $\begin{array}{l}\text { Saya dapat memilih model, metode atau } \\
\text { media yang disesuaikan dengan gaya } \\
\text { mengajar saya dengan perbedaan } \\
\text { kemampuan siswa }\end{array}$ & 75 & $\begin{array}{l}\text { Sangat } \\
\text { Baik }\end{array}$ \\
\hline 9 & $\begin{array}{l}\text { Saya tidak mengetahui model, metode } \\
\text { atau media yang tepat untuk diterapakan } \\
\text { dalam pembelajaran }\end{array}$ & 93 & $\begin{array}{c}\text { Sangat } \\
\text { Baik }\end{array}$ \\
\hline 10 & Saya dapat menggunakan berbagai & 74 & Baik \\
\hline
\end{tabular}




\begin{tabular}{|c|c|c|c|}
\hline & metode dan teknik penilaian & & \\
\hline 11 & $\begin{array}{l}\text { Saya dapat menganalisis hasil penilaian } \\
\text { dari berbagai aspek (ranah kognitif, ranah } \\
\text { afektif dan ranah psikomotorik) }\end{array}$ & 78 & $\begin{array}{l}\text { Sangat } \\
\text { Baik }\end{array}$ \\
\hline 12 & $\begin{array}{l}\text { Saya kesulitan dalam melakukan analisis } \\
\text { penilaian dari berbagai aspek (ranah } \\
\text { afektif, raanah psikomotorik, dan ranah } \\
\text { kognitif) }\end{array}$ & 69 & Baik \\
\hline 13 & $\begin{array}{l}\text { Saya dapat menilai kinerja siswa didalam } \\
\text { kelas. }\end{array}$ & 76 & $\begin{array}{l}\text { Sangat } \\
\text { Baik }\end{array}$ \\
\hline 14 & $\begin{array}{l}\text { Saya tidak mengikuti perkembangan } \\
\text { teknologi Saya tidak melakukan penilaian } \\
\text { kinerja siswa }\end{array}$ & 73 & Baik \\
\hline 15 & $\begin{array}{l}\text { Saya dapat mengembangkan potensi dan } \\
\text { mengatasi kekurangan peserta didik }\end{array}$ & 69 & Baik \\
\hline \multirow[t]{2}{*}{16} & $\begin{array}{l}\text { Saya tidak peduli terhadap } \\
\text { pengembangan potensi peserta didik }\end{array}$ & 76 & $\begin{array}{c}\text { Sangat } \\
\text { Baik }\end{array}$ \\
\hline & Total & 76,8 & $\begin{array}{l}\text { Sangat } \\
\text { Baik }\end{array}$ \\
\hline
\end{tabular}

Kemampuan Pedagogical Knowledge (PK) mahasiswa calon guru Pendidikan Biologi UIN Raden Intan Lampung dikategorikan dalam kriteria sangat baik dengan skor rata-rata 76,8\%. Terdapat 3 item dalam kategori baik yaitu kemampuan dalam mengembangkan potensi dan mengatasi kekurangan peserta didik, penggunaan berbagai metode dan teknik penilaian dan kesulitan melakukan analisis penilaian dari berbagai aspek. Pada item pernyataan ada beberapa pernyataan negatif (-) yang berperan sebagai pengecoh.

\section{Pedagogical Content Knowledge (PCK)}

Berdasarkan analisis data, diketahui kemampuan Pedagogical Content Knowledge (PCK) mahasiswa calon guru Pendidikan Biologi UIN Raden Intan Lampung disajikan dalam tabel 3 dibawah ini.

Tabel 3. Kemampuan pedagogical content knowledge (PCK).

\begin{tabular}{|c|l|c|c|}
\hline No & \multicolumn{1}{|c|}{ Item Pernyataan } & Persentase & Kriteria \\
\hline 1 & $\begin{array}{l}\text { Saya mampu membuat siswa aktif untuk } \\
\text { memecahkan masalah biologi sesuai } \\
\text { dengan topik yang sedang dibahas }\end{array}$ & 83 & $\begin{array}{c}\text { Sangat } \\
\text { Baik }\end{array}$ \\
\hline 2 & $\begin{array}{l}\text { Saya tidak membimbing siswa untuk } \\
\text { memecahkan masalah biologi terkait } \\
\text { topik yang dibahas }\end{array}$ & 65 & 83 \\
\hline 3 & $\begin{array}{l}\text { Saya tidak mengerti cara } \\
\text { mengembangkan perangkat }\end{array}$ & $\begin{array}{c}\text { Sangat } \\
\text { Baik }\end{array}$ \\
\hline
\end{tabular}

Nukhbatul Bidayati Haka, Rizka Yohana, dkk.: Technological Pedagogical Content Knowledge Mahasiswa Calon Guru Biologi dalam Menyusun Perangkat Evaluasi Pembelajaran |79 


\begin{tabular}{|c|c|c|c|}
\hline & pembelajaran secara utuh & & \\
\hline 4 & $\begin{array}{l}\text { Saya memilih pendekatan dan strategi } \\
\text { pengajaran yang efektif }\end{array}$ & 78 & $\begin{array}{l}\text { Sangat } \\
\text { Baik }\end{array}$ \\
\hline 5 & $\begin{array}{l}\text { Saya tidak mempertimbangkan } \\
\text { model/metode yang cocok dengan } \\
\text { materi biologi yang di ajarkan }\end{array}$ & 70 & Baik \\
\hline 6 & $\begin{array}{l}\text { Saya membantu siswa saya memahami } \\
\text { materi biologi dengan berbagai strategi } \\
\text { sesuai kurikulum }\end{array}$ & 72 & Baik \\
\hline 7 & $\begin{array}{l}\text { Saya kurang memahami kurikulum } \\
\text { sehingga penerapan model dan metode } \\
\text { terkesan itu-itu saja }\end{array}$ & 86 & $\begin{array}{l}\text { Sangat } \\
\text { Baik }\end{array}$ \\
\hline 8 & $\begin{array}{l}\text { Saya mengembangkan evaluasi } \\
\text { pembelajaran untuk mengukur } \\
\text { penguasaan siswa terhadap materi } \\
\text { biologi yang saya ajarkan }\end{array}$ & 82 & $\begin{array}{c}\text { Sangat } \\
\text { baik }\end{array}$ \\
\hline \multirow[t]{2}{*}{9} & $\begin{array}{l}\text { Saya tidak mengembangkan evaluasi } \\
\text { pembelajaran }\end{array}$ & 76 & $\begin{array}{c}\text { Sangat } \\
\text { Baik }\end{array}$ \\
\hline & Total & 68,33 & Baik \\
\hline
\end{tabular}

Kemampuan Pedagogical Content Knowledge (PCK) mahasiswa calon guru Pendidikan Biologi UIN Raden Intan Lampung dikategorikan dalam kriteria baik dengan skor rata-rata $68,33 \%$. Terdapat 3 item dikategorikan dalam kriteria baik dan 2 diantaranya merupakan jenis pernytaan negative dengan tingkat pengecoh yang tinggi.

\section{Technological Knowledge (TK)}

Berdasarkan analisis data, diketahui kemampuan Technological Knowledge (TK) mahasiswa calon guru Pendidikan Biologi UIN Raden Intan Lampung disajikan dalam tabel 4 dibawah ini.

Tabel 4. Kemampuan technological knowledge (TK).

\begin{tabular}{|l|l|c|c|}
\hline No & \multicolumn{1}{|c|}{ Item Pernyataan } & Persentase & Kriteria \\
\hline 1 & $\begin{array}{l}\text { Saya mengoperasikan dan mengatasi } \\
\text { masalah teknis pada komputer }\end{array}$ & 71 & Baik \\
\hline 2 & $\begin{array}{l}\text { Saya dapat mengoperasikan printer, } \\
\text { scanner, projector, ujian online, LCD dan } \\
\text { camera }\end{array}$ & $\begin{array}{c}\text { Sangat } \\
\text { Baik }\end{array}$ \\
\hline 3 & $\begin{array}{l}\text { Saya kesulitan dalam menggunakan } \\
\text { printer, scanner, projector, ujian online, } \\
\text { LCD dan camera serta perangkat } \\
\text { teknologi lainnya. }\end{array}$ & $\begin{array}{c}\text { Sangat } \\
\text { Baik }\end{array}$ \\
\hline
\end{tabular}




\begin{tabular}{|l|l|c|c|}
\hline Total & 79 & $\begin{array}{c}\text { Sangat } \\
\text { Baik }\end{array}$ \\
\hline
\end{tabular}

Kemampuan Technological Knowledge (TK) mahasiswa calon guru Pendidikan Biologi UIN Raden Intan Lampung dikategorikan daam kriteria sangat baik dengan skor rata-rata 79\%. Terdapat 2 item yang dikategorikan dalam kriteria sangat baik dan satu diantaranya merupakan pernyataan negative dengan tingkat pengeoh yang tinggi.

\section{Technological Pedagogical Knowledge (TPK)}

Berdasarkan analisis data, diketahui kemampuan Technological Pedagogical Knowledge (TPK) mahasiswa calon guru Pendidikan Biologi UIN Raden Intan Lampung disajikan dalam tabel 5 dibawah ini.

Tabel 5. Kemampuan technological pedagogical knowledge (TPK).

\begin{tabular}{|l|l|c|c|}
\hline No & \multicolumn{1}{|c|}{ Item Pernyataan } & Persentase & Kriteria \\
\hline 1 & $\begin{array}{l}\text { Saya memilih teknologi yang sesuai } \\
\text { dengan pendekatan dan strategi } \\
\text { pembelajaran di kelas }\end{array}$ & $\begin{array}{c}\text { Sangat } \\
\text { Baik }\end{array}$ \\
\hline 2 & $\begin{array}{l}\text { Saya menyesuaikan media dan pemilihan } \\
\text { teknologi dengan materi biologi yang } \\
\text { akan diajarkan }\end{array}$ & 66 & Baik \\
\hline 3 & $\begin{array}{l}\text { Saya dapat mengaplikasikan aplikasi- } \\
\text { aplikasi komputer yang berkaitan dengan } \\
\text { teknologi kedalam pembuatan perangkat } \\
\text { pembelajaran }\end{array}$ & 72 & Baik \\
\hline & \begin{tabular}{l} 
Total \\
\hline
\end{tabular}
\end{tabular}

Kemampuan Technological Pedagogical Knowledge (TPK) mahasiswa calon guru Pendidikan Biologi UIN Raden Intan Lampung dikategorikan dalam kriteria baik dengan skor rata-rata $71 \%$. Terdapat 2 item yang berada dalam kategori baik yaitu penyesuaian media dan pemilihan teknologi yang tepat dalam pembelajaran dan menggunakan teknologi sebagai media dalam pembelajaran.

\section{Technological Content Knowledge (TCK)}

Berdasarkan analisis data, diketahui kemampuan Technological Content Knowledge (TCK) mahasiswa calon guru Pendidikan Biologi UIN Raden Intan Lampung disajikan dalam tabel 6 dibawah ini.

Tabel 6. Kemampuan technological content knowledge (TCK).

\begin{tabular}{|l|l|c|c|}
\hline No & \multicolumn{1}{|c|}{ Item Pernyataan } & Persentase & Kriteria \\
\hline 1 & $\begin{array}{l}\text { Saya menggunakan aplikasi komputer } \\
\text { dalam pembelajaran }\end{array}$ & 82 & $\begin{array}{c}\text { Sangat } \\
\text { Baik }\end{array}$ \\
\hline 2 & Saya mengakses internet untuk & 82 & Sangat \\
\hline
\end{tabular}

Nukhbatul Bidayati Haka, Rizka Yohana, dkk.: Technological Pedagogical Content Knowledge Mahasiswa Calon Guru Biologi dalam Menyusun Perangkat Evaluasi Pembelajaran |81 


\begin{tabular}{|l|l|c|c|}
\hline menambah pengetahuan & & Baik \\
\hline Total & $\mathbf{8 2}$ & $\begin{array}{c}\text { Sangat } \\
\text { Baik }\end{array}$ \\
\hline
\end{tabular}

Kemampuan Technological Content Knowledge (TCK) mahasiswa calon guru Pendidikan Biologi UIN Raden Intan Lampung dikategorikan dalam kriteria sangat baik dengan skor rata-rata $82 \%$.

\section{Technological Pedagogical Content Knowledge (TPCK)}

Berdasarkan analisis data, diketahui kemampuan Technological Pedagogical Content Knowledge (TPCK) mahasiswa calon guru Pendidikan Biologi UIN Raden Intan Lampung disajikan dalam tabel 7 dibawah ini.

Tabel 7. Kemampuan technological pedagogical content knowledge (TPCK).

\begin{tabular}{|l|l|c|c|}
\hline No & \multicolumn{1}{|c|}{ Item Pernyataan } & Persentase & Kriteria \\
\hline 1 & $\begin{array}{l}\text { Saya menerapkan perpaduan } \\
\text { pengetahuan biologi, pedagogic, dan } \\
\text { teknologi yang dimiliki untuk mewujudkan } \\
\text { pembelajaran yang efektif. }\end{array}$ & $\begin{array}{c}\text { Sangat } \\
\text { Baik }\end{array}$ \\
\hline 2 & $\begin{array}{l}\text { Saya mengembangkan strategi, } \\
\text { model/metode pembelajaran dan } \\
\text { teknologi yang sesuai dengan materi } \\
\text { biologi yang disampaikan }\end{array}$ & 74 & Baik \\
\hline 3 & $\begin{array}{l}\text { Saya memantau siswa melalui } \\
\text { pembelajaran mereka sendiri }\end{array}$ & 72 & Baik \\
\hline 4 & $\begin{array}{l}\text { Saya cenderung menerapkan strategi } \\
\text { pembelajaran dan menggunakan aplikasi } \\
\text { komputer yang monoton }\end{array}$ & 73 & Baik \\
\hline & \begin{tabular}{l} 
Total \\
\hline
\end{tabular} & $\mathbf{7 4}$ & Baik \\
\hline
\end{tabular}

Kemampuan Technological Pedagogical Content Knowledge (TPCK) mahasiswa calon guru Pendidikan Biologi UIN Raden Intan Lampung dikategorikan dalam kriteria baik dengan skor rata-rata $74 \%$. Terdapat 1 item dengan kriteria sangat baik yaitu kemampuan dalam memadukan pengetahuan biologi, pedagogik dan teknologi dalam pembelajaran di kelas.

Berdasarkan perolehan hasil dari angket pengukuran kemampuan Technological Pedagogical Content Knowledge (TPCK) mahasiswa Pendidikan Biologi UIN Raden Intan Lampung angkatan 2016 dengan jumlah 47 butir pernyataan yang terdiri dari pernyataan negatif dan pernyataan positif, yang terdiri dari 7 indikator. Didapatkan skor untuk CK sebesar 78,5\%, PK 76,8\%, PCK 68,33\%, TK 79\%, TPK 71\%, TCK 82\%, dan TPCK 74\%. Skor tersebut berdasarkan angket yang telah diisi oleh mahasiswa dengan total sampel yang digunakan sebanyak 48 mahasiswa. 


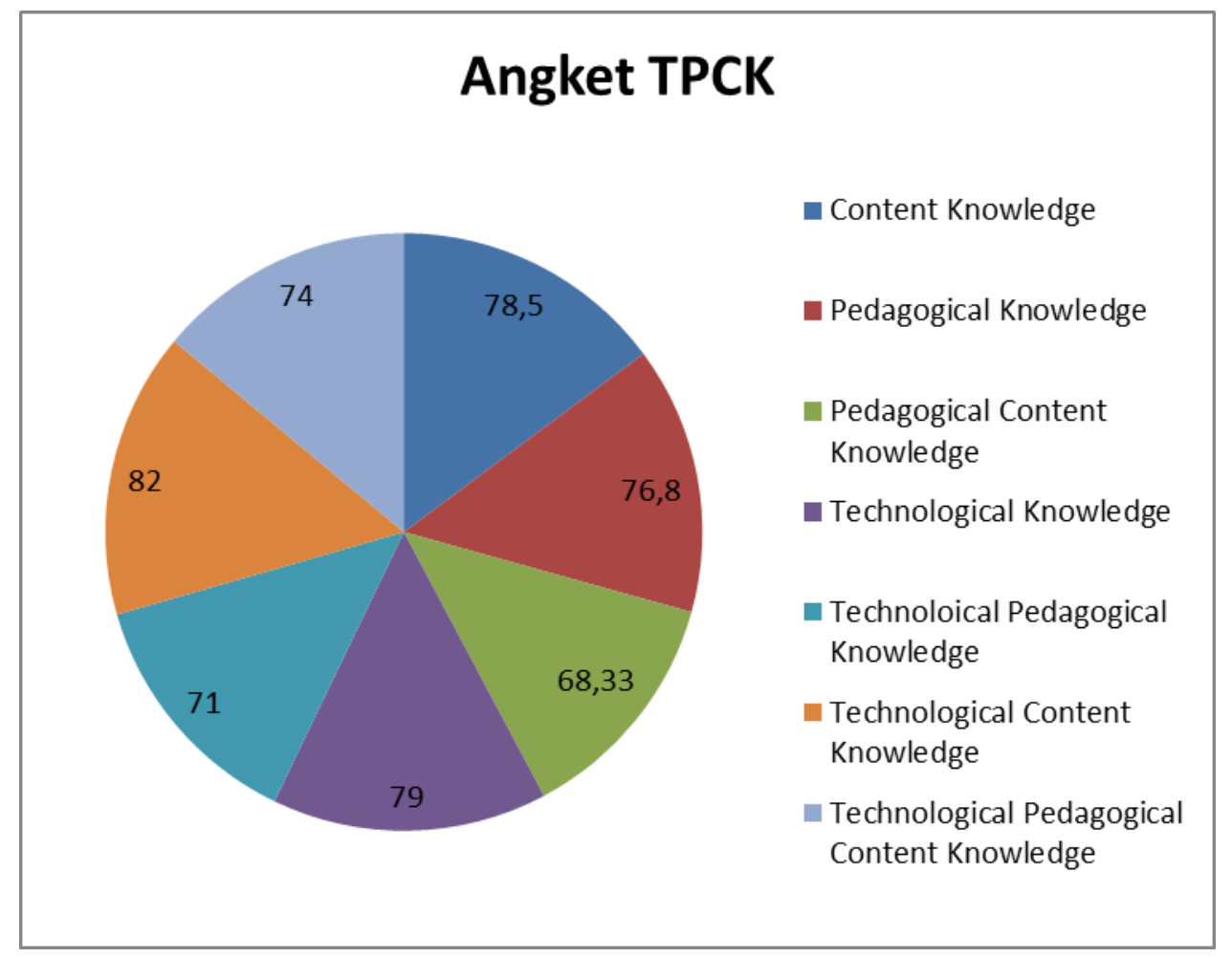

Instrument yang digunakan di dalam penelitian ini adalah kuesioner tertutup yang berisi pernyataan yang harus diisi oleh mahassiwa tentang kesetujuan atau ketidaksetujuan mereka terhadap pernyataan-pernyataan yang diberikan dalam angket (skala linkert). Pernyataan-pernyataan yang dibuat disesuaikan dengan aspek TPCK yang mecakup 7 komponen yaitu Technological Knowledge (TK), Technological Content Knowledge (TCK), Technological Pedagogical Knowledge (TPK), Pedagogical Knowledge (PK), Content Knowledge (CK), Pedagogical Content Knowledge (PCK) dan Technological Pedagogical Content Knowledge (TPCK). Kuesioner TPCK terdiri atas 61 pernyataan yang harus diisi oleh responden.

Gambar 1 menunjukan bahwa kemampuan TPCK yang dimiliki oleh mahasiswa calon guru Pendidikan Biologi UIN Raden Intan Lampung tergolong baik. Komponen pengetahuan yang memiliki skor tertinggi adalah TCK yaitu pengetahuan tentang konten teknologi dengan skor rata-rata $82 \%$. Hal ini menunjukan bahwa kemampuan yang dimiliki oleh mahasiswa dalam menginterprestasikan teknologi kedalam pembelajaran sudah baik. Sedangkan skor rata-rata terendah terdapat pada komponen PCK yaitu pengetahuan tentang cara menyajikan materi dengan nilai $68,33 \%$. Hal ini menunjukan mahasiswa masih kurang mampu menginteprestasikan kemampuan pedagogik dengan pengetahuan kedalam pemebelajaran. Program magang yang dilaksanakan oleh calon guru pendidikan biologi merupakan kegiatan yang memberikan pengalaman awal untuk membangun jati diri pendidik, memantabkan kemampuan awal calon guru, mengembangkan perangkat pembelajaran dan kecakapan pedagogis yang berguna dalam membangun bidang keahlian pendidik. Pada program magang yang dilakukan mahasiswa membuat rencana pelaksanaan pembelajaran yang dianalisis dan dikaitkan dengan kemampuan TPCK yang dimiliki berdasarkan angket yang telah diisi oleh mahasiswa. Hasil analisis tersebut dikaitkan dipaparkan pada Gambar 1. 


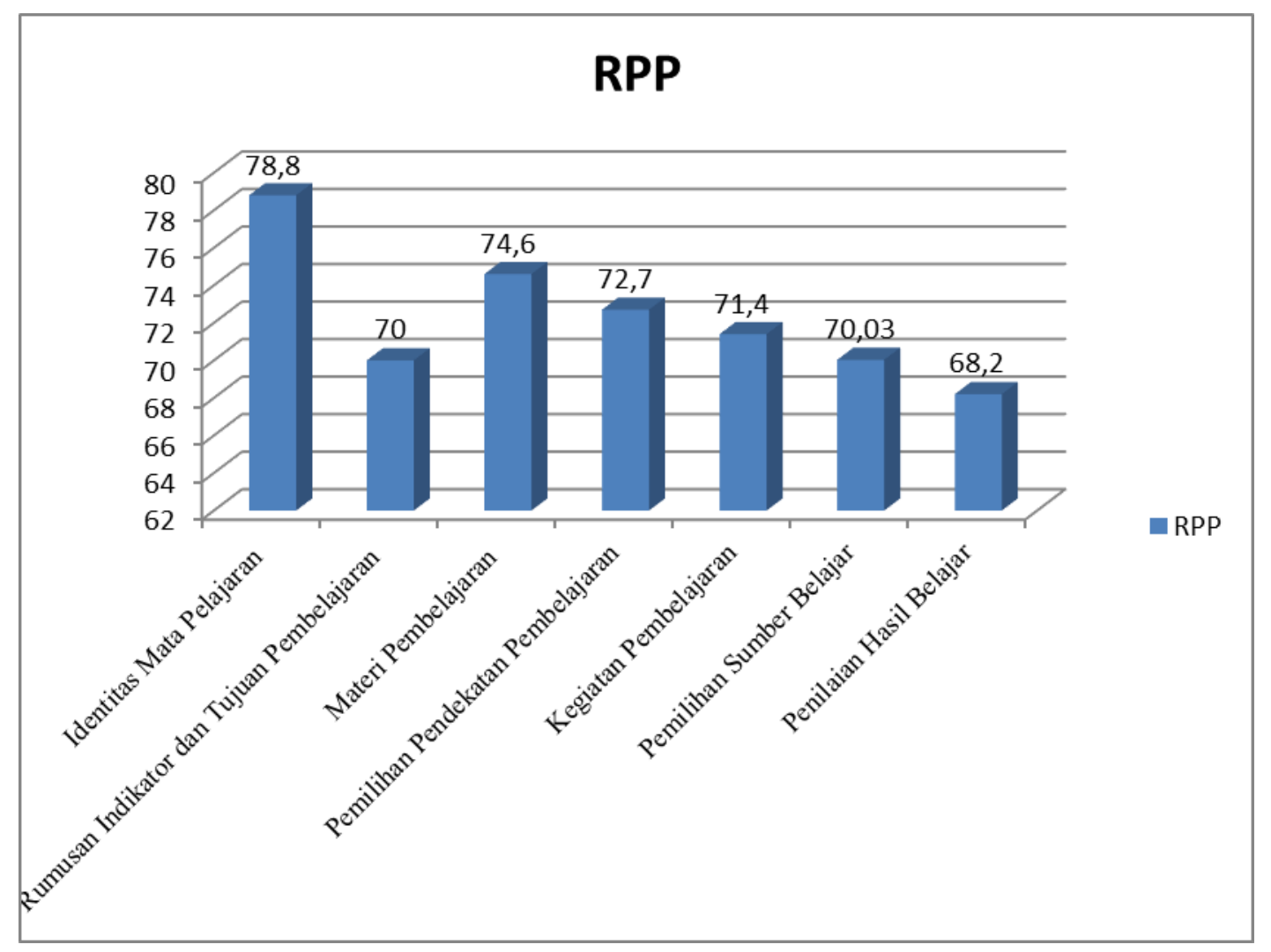

Gambar 1. Penilaian RPP yang telah dibuat mahasiswa

Gambar 1 menunjukan bahwa hasil lembar observasi RPP Dalam kategori sedang. Dari beberapa komponen diatas skor tertinggi terdapat pada indikator identitas mata pelajaran. Identitas mata pelajaran ini mencakup mencantumkan nama dan satuan pendidikan, mata pelajaran, kelas, semester, kompetensi inti, kompetensi dasar, tujuan, dan alokasi waktu. Sedangkan skor terendah pada penilaian hasil belajar yang mencakup keseuaian teknik penilaian, butir instrument kejelasan prosedur penilaian dan keberadaan instrument, kunci jawaban soal dan rubrik penilaian. Pada indikator ini terdapat persentase terendah yaitu $54 \%$ yang berada dalam kategori cukup mancakup keberadaan dan kejelasan mengenai prosedur penilaian. Penilaian yang dimaksud disni berupa penilaian afektif, psikomotorik dan kognitif pada peserta didik yang nantinya akan mengacu kepada perangkat evaluasi hasil belajar. Rata-rata mahasiswa hanya menyajikan penilaian kognitif dan psikomotorik tanpa penilaian afektif. Selain angket dan lembar observasi mengenai kemampuan TPCK dilakukan juga analisis tentang perangkat evaluasi pembelajaran disajikan dalam Gambar 3. 


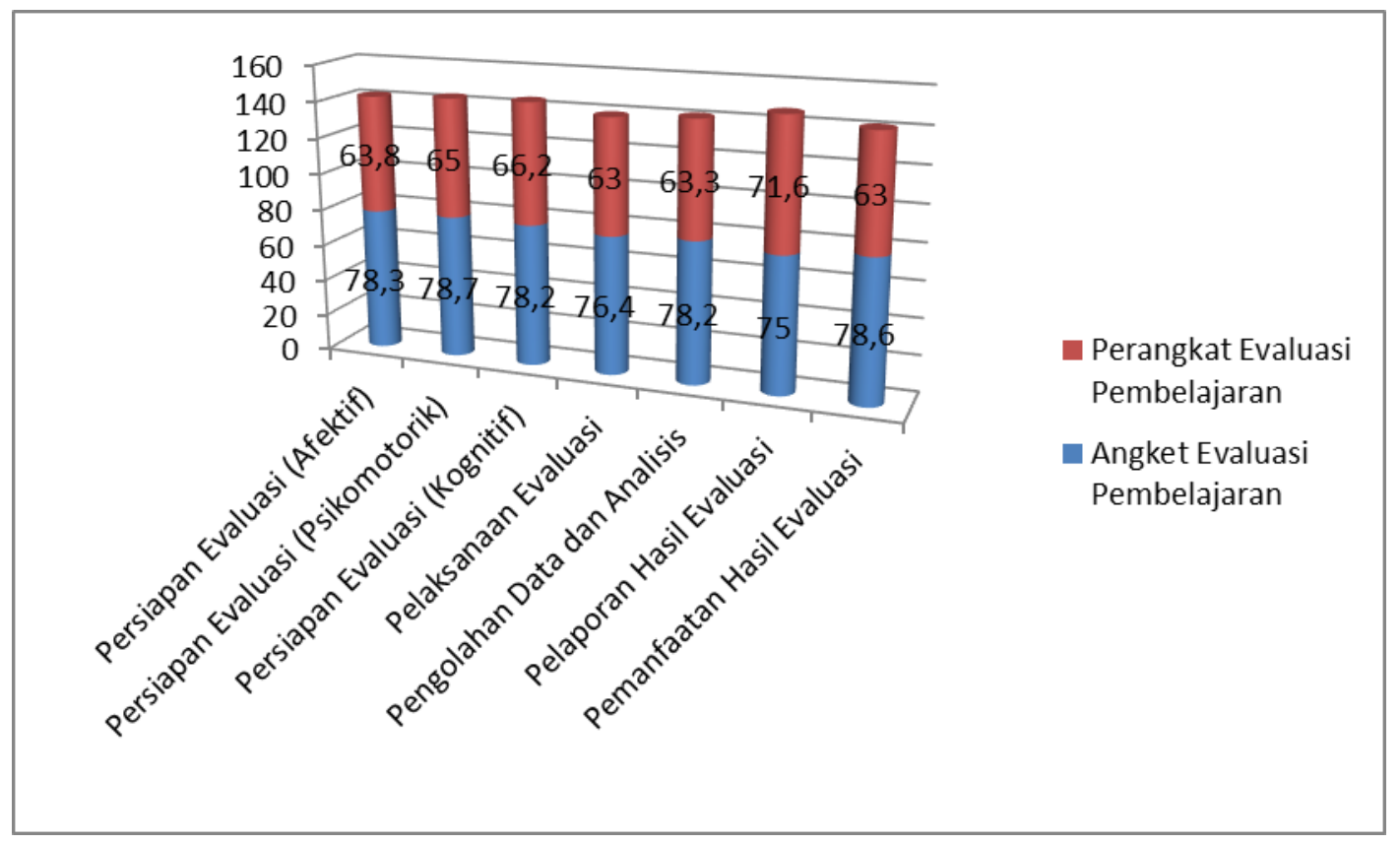

Gambar 2. Penilaian angket dan perangkat evaluasi pembelajaran yang teah dibuat mahasiswa

Instrument yang digunakan di dalam penelitian ini adalah kuesioner tertutup yang berisi pernyataan yang harus diisi oleh mahassiwa tentang kesetujuan atau ketidaksetujuan mereka terhadap pernyataan-pernyataan yang diberikan dalam angket (skala linkert). Angket ini terdiri dari 64 penytaan yang harus diisi oleh mahasiswa. Prosedur pengembangan evaluasi pembelajaran terdiri atas: (1) perencanaan evaluasi yang meliputi analisis kebutuhan, merumuskan tujuan evaluasi, menyusun kisi-kisi, mengembangkan draf instrumen, uji coba dan analisi, merevisi dan menyusun instrument final, (2) pelaksanaan evaluasi dan monitoring, (3) pengolahan data dan analisis, (4) pelaporan hasil evaluasi dan (5) pemanfaatan hasil evaluasi (Suharsimi Arikunto 2010). Berdasarkan data hasil penelitian menggunakan angket dan lembar observasi, perencanaan evaluasi dibagi menjadi 3 yaitu pada ranah afektif, psikomotik dan kognitif. Selain angket digunakan pula lembar observasi berupa dokumen berupa perangkat evaluasi yang telah dibuat mahasiswa. Dari penjelasan diatas dapat diketahui bahwa kemampuan mahasiswa dalam membuat perangkat evaluasi dari tiap ranah penilaian yang mencakup analisis kebutuhan, tujuan penilaian, identifikasi kompetensi, penyususnan kisi-kisi penilaian dan pedoman penskoran sudah tergolong baik tetapi masih perlu ditingkatkan mengingat pada penilaian afektif penyusunan pedoman penskoran dengan skor rata-rata $63 \%$ masuk dalam kategori cukup.

Pada penelitian ini melihat adanya hubungan antara kemampuan Technological Pedagogical Content Knowledge (TPCK) yang dikaitkan dengan kemampuan dalam menyusun perangkat evaluasi pembelajaran pada mahasiswa Pendidikan Biologi UIN Raden Intan Lampung. Dijelaskan dalam tabel 2.

Tabel 2. Hasil korelasi antara kemampuan TPCK dengan kemampuan membuat perangkat pembelajaran 


\section{Correlations}

\begin{tabular}{|cc|c|c|}
\hline & & TPCK & EVAPEM \\
\hline TPCK & Pearson Correlation & 1 & $.585^{* *}$ \\
Sig. (2-tailed) & & .000 \\
$\mathrm{~N}$ & 48 & 48 \\
\hline EVAPEM Pearson Correlation & $.585^{* *}$ & 1 \\
Sig. (2-tailed) & .000 & \\
$\mathrm{~N}$ & 48 & 48 \\
\hline
\end{tabular}

**. Correlation is significant at the 0.01 level (2tailed).

Hasil analisis menggunakan Korelasi Product Moment dengan bantuan program SPSS Versi 16.0 menunjukan koefisien korelasi antara kemampuan Technological Pedagogical Content Knowledge (TPCK) dengan kemampuan membuat perangkat Evaluasi Pembelajaran pada mahasiswa yaitu sebesar 0,585 >0,05 hal ini menunjukan ada korelasi positif antara variabel $\mathrm{X}$ dan variabel $\mathrm{Y}$. Hubungan tersebut masuk dalam kategori sedang pada rentang 0,400 - 0,599. Berdasarkan data output pada program SPSS Versi 16.0 seperti yang tertera pada tabel didapat hasil sig. (2-tailed) $0,00<0,05$ artinya hubungan dua variabel tersebut bersifat signifikan baik pada taraf signifikan 0,05 hal ini dapat dilihat pada tabel koefisien korelasi diatas. Diketahui pula bahwa interpretasi $\mathrm{df}=48$ dimana $r$ pada taraf signifikan $5 \%$ sebesar 0,284 sedangkan $r_{x y}$ diperoleh 0,585 yang merupakan hubungan yang sedang dan signifikan maka hipotesis pada penelitian ini :

$\mathrm{Ha}=$ Terdapat hubungan antara kemampuan Technological Pedagogical Content Knowledge (TPCK) dengan kemampuan membuat perangkat Evaluasi Pembelajaran pada mahasiswa.

Ho = Tidak ada hubungan antara kemampuan Technological Pedagogical Content Knowledge (TPCK) dengan kemampuan membuat perangkat Evaluasi

Ho : $r_{x y}=0$ Pembelajaran pada mahasiswa.

Ho : $r_{x y} \neq 0$

Dengan demikian setelah diterima hasil output SPSS pada tabel diatas yaitu nilai $p$ $=0,00<0,05$ artinya hubungan dua variabel tersebut bersignifikan baik pada taraf 0,05. Maka hipotesa (Ho) yang berbunyi "Tidak ada hubungan antara kemampuan Technological Pedagogical Content Knowledge (TPCK) dengan kemampuan membuat perangkat Evaluasi Pembelajaran pada mahasiswa" ditolak, sedangkan "Terdapat hubungan antara kemampuan Technological Pedagogical Content Knowledge (TPCK) dengan kemampuan membuat perangkat Evaluasi Pembelajaran pada mahasiswa" diterima. 
Dari data hasil penelitian ini dapat diinterprestasikan bahwa kemampuan Technological Pedagogical Content Knowledge (TPCK) dengan kemampuan membuat perangkat Evaluasi Pembelajaran memiliki hubungan searah yaitu semakin baik kemampuan Technological Pedagogical Content Knowledge (TPCK) maka semakin baik juga hasil perangkat Evaluasi Pembelajaran yang dibuat oleh mahasiswa Pendidikan Biologi UIN Raden Intan Lampung angkatan 2016. Hasil korelasi dalam penelitian ini merupakan korelasi positif dengan tingkat sedang dan signifikan.

\section{KESIMPULAN}

Berdasarkan hasil penelitian dan pembahasan tentang korelasi antara kemampuan Technological Pedagogical Content Knowledge (TPCK) mahasiswa calon guru Pendidikan Biologi UIN Raden Intan Lampung dalam menyusun Peraangkat Evaluasi Pembelajaran dapat disimpulkan: Kemampuan Technological Pedagogical Content Knowledge (TPCK) mahasiswa calon guru Pendidikan Biologi UIN Raden Intan Lampung dalam menyusun Peraangkat Evaluasi Pembelajaran memperoleh rata-rata sebesar 63,11\% dengan kriteria baik, kemampuan calon guru Pendidikan Biologi UIN Raden Intan Lampung dalam menyusun Peraangkat Evaluasi Pembelajaran memperoleh rata-rata 60,94\% dengan kriteria baik dan terdapat korelasi antara kemampuan Technological Pedagogical Content Knowledge (TPCK) mahasiswa calon guru Pendidikan Biologi UIN Raden Intan Lampung dalam menyusun Peraangkat Evaluasi Pembelajaran. Hal ini dapat dilihat dari nilai sig. korelasi pada taraf 0,05 sebesar 0,00<0,05, nilai Pearson Correlation 0,58 $>0,05$, dan koefisien determinasi $32 \%$, berarti bahwa terdapat korelasi positif dengan tingkat sedang dan signifikan antara variabel $\mathrm{X}$ dengan variabel $\mathrm{Y}$.

\section{DAFTAR PUSTAKA}

Aulia Novitasari. Alinis Ilyas. Siti NA. (2017). "Pengaruh Model Pembelajaran Inkuiri Terbimbing Terhadap Keterampilan Proses Sains Peserta Didik Pada Materi Fotosintesis Kelas XII IPA Di SMA Yadika Bandar Lampung. Bandar Lampung." BIOSFER Jurnal Tadris Pendidikan Biologi. 8 (1): 92.

D. Rochintaniawati, R. Riandi, J. Kestianti dkk. (2019). "The Analysis Of Biology Teachers' Technological Pedagogical Content Knowledge Development In Lesson Study In West Java Indonesia. Bandung." Jurnal Pendidikan IPA Indonesia.

Dwi Anis AD, Hariyatmi. (2017). "Kemampuan Technological Knowledge (TK) Calon Guru Biologi FKIP UMS."

Eka Ariyati. n.d. (2018) "Kemampuan Pedagogical Content Knowledge Calon Guru Biologi Menyusun RPP Pada Praktik Microteaching." Jurnal Pendidikan.

M.J Koehler, P. Mishra \& W. n.d. "Cain. What Is Technological Pedagogical Content Knowedge (TAPCK)." Jurnal of Education.

Nur Atikah. (2019). "Korelasi Keterampilan Technological Pedagogical Content Knowledge (TPCK) Dengan Kompetensi Profesional Guru Biologi Di SMA Kecamatan Seberang Ulu II Palembang."

Nurul, H. (2017). "Kemampuan TPCK Guru Biologi Kelas X SMA Muhammadiyah Sekota Surakarta Dalam Penyusunan RPP ." 
Sri, S. dkk. (2017). "Analisis Kemampuan Technological Pedagogical And Content Knowledge (TPACK) Calon Guru Pada Mata Kuliah PP Bio."

Sugiyono. (2017). Metode Peneitian Pendidikan Kuantitatif, Kualitatif, Dan R\&D. Bandung: Alfabeta.

Suharsimi Arikunto. (2010). Prosedur Penelitian Suatu Pendekatan Praktik. jakarta: Rineka Cipta.

Zainal Arifin. (2013). Evaluasi Pembelajaran Prinsip, Teknik, Prosedur. Bandung: PT Remaja Rosdakarya. 